\title{
Influence of nanoparticles on color stability, microhardness, and flexural strength of acrylic resins specific for ocular prosthesis
}

This article was published in the following Dove Press journal:

International Journal of Nanomedicine

10 December 2014

Number of times this article has been viewed

\section{Agda Marobo Andreotti \\ Marcelo Coelho Goiato \\ Amália Moreno \\ Adhara Smith Nobrega \\ Aldiéris Alves Pesqueira \\ Daniela Micheline dos \\ Santos}

Araçatuba Dental School, São Paulo State University, Araçatuba, São Paulo, Brazil
Correspondence: Daniela Micheline dos Santos

Department of Dental Materials and Prosthodontics, Araçatuba Dental School, São Paulo State University José Bonifácio, I 193, Vila Mendonça, Araçatuba,

São Paulo, Brazil 160I5-050

$\mathrm{Fax}+551836363287$

Email danielamicheline@foa.unesp.br

\begin{abstract}
The aim of this study was to assess the effect of adding nanoparticles to N1 acrylic resin intended for artificial sclera, in terms of the color stability, microhardness, and flexural strength of the resin. Three hundred samples of N1 acrylic resin were used: 100 samples for color stability and microhardness tests (each test was performed on the opposite side of each sample), and 200 samples for flexural strength testing (100 samples before and after 1,008 hours of accelerated aging). Samples for each test were separated into ten groups $(n=10)$, ie, without nanoparticles (control group) or with nanoparticles of zinc oxide, titanium dioxide $\left(\mathrm{TiO}_{2}\right)$, and barium sulfate at weight concentrations of $1 \%, 2 \%$, and $2.5 \%$ (nanoparticle groups). Data were subjected to statistical analysis with nested analysis of variance and Tukey's test $(P<0.05$ significance level). Among the nanoparticle groups, the $\mathrm{TiO}_{2}$ groups showed better color stability at all concentrations. Microhardness values increased after artificial aging, except for the control and zinc oxide groups. After aging, the $1 \%-2 \% \mathrm{TiO}_{2}$ groups had significantly higher microhardness values compared with the other nanoparticle groups. Before aging, there was a significant difference in flexural strength between the control and nanoparticle groups. After aging, the control and $\mathrm{TiO}_{2}$ groups, regardless of concentration, showed the lowest flexural strength values. Incorporation of nanoparticles directly influenced the acrylic resin properties, with $\mathrm{TiO}_{2}$ being the most influential nanoparticle in terms of the evaluated properties.
\end{abstract}

Keywords: acrylic resins, eye, artificial, color, hardness, nanoparticles

\section{Introduction}

Ocular absence leads to difficulties in establishing social relationships, in addition to functional, emotional, personal, and esthetic disorders. ${ }^{1}$ Ocular prostheses can restore and beautify a face with compromised expression, offering a safe, aesthetic, and satisfactory alternative to rehabilitate anophthalmic patients. ${ }^{2,3}$ Materials used for ocular rehabilitation demand excellent esthetics, durability, adaptation, and biocompatibility. ${ }^{4-7}$ For these reasons, white and colorless acrylic resins are the materials of choice for these prostheses. ${ }^{6-9}$

One of the main reasons for refabrication of ocular prostheses is color degradation. Other problems affecting ocular prostheses include changes in the superficial microhardness and flexural strength over time, which directly influence material longevity. Currently, most of the research in this area focuses on optimizing prosthesis performance by improving the physical and mechanical properties of the prosthesis material. Several studies have found satisfactory results by incorporating nanoparticles (NPs) into polymeric materials (mainly silicone elastomers used for facial prostheses), in terms of protecting such materials from degradation. ${ }^{10-16}$ Research has 
been directed towards the development of a new industrial process incorporating NPs into a polymeric matrix, with the goal of providing a new class of polymeric materials that offer the resistance of NPs and the flexibility of organic polymer matrices. ${ }^{17-19}$

According to a survey of the literature, NPs that are widely used in industry include zinc oxide $(\mathrm{ZnO})$, titanium dioxide $\left(\mathrm{TiO}_{2}\right)$, and barium sulfate $\left(\mathrm{BaSO}_{4}\right)$. The addition of $\mathrm{TiO}_{2}{ }^{20}$ and $\mathrm{ZnO}$ to polymers can improve the mechanical and optical properties of polymers due to the small size, large specific area, and quantum effect of the NPs, as well as the strong interfacial interaction between the organic polymer and inorganic NPs. ${ }^{21,22}$ The NPs hardly scatter any visible light, being optically transparent, specially due to their nanometer scale and low content, ${ }^{22}$ in addition to exhibiting a high refractive index. ${ }^{20} \mathrm{BaSO}_{4}$ is used in medical applications to examine the esophagus, stomach, and intestine by X-ray or computed tomography, as well as to confer higher radiopacity to rootend filling materials. In the cosmetic industry, $\mathrm{BaSO}_{4}$ is used in sunscreen lotions to create a physical barrier against ultraviolet rays and to provide a better product appearance. ${ }^{15,16}$

In addition to improving polymer properties, it has been suggested that incorporating NPs into an organic polymer could provide resistance to environmental stress-related cracking and aging. ${ }^{23}$ However, to date, no study has been performed to examine the influence of NPs on the physical and mechanical properties of acrylic resins specific for artificial sclera. Thus, this study aimed to evaluate the influence of accelerated aging and different $\mathrm{NP}$ types $\left(\mathrm{ZnO}, \mathrm{TiO}_{2}\right.$, and $\left.\mathrm{BaSO}_{4}\right)$ and concentrations $(1 \%, 2 \%$, and $2.5 \%)$, in terms of the color stability, microhardness, and flexural strength of $\mathrm{N} 1$ acrylic resin for artificial sclera. The null hypothesis of the study was that addition of NPs would not influence the characteristics of acrylic resin according to the different types and concentrations of NPs used, and would be consistent over the periods studied.

\section{Materials and methods Energy dispersive spectroscopy and scanning electron microscopy}

To verify whether the acrylic resin contained any of the evaluated NPs in its composition, the chemical components of the resin were mapped through energy dispersive spectroscopy (EDS) in combination with scanning electron microscopy (SEM) analysis (EDS-SEM). Small volumes $\left(1 \mu \mathrm{m}^{3}\right)$ of the acrylic resin surface were characterized by EDS under $10,000 \times$ magnification, associated with SEM analysis of the images (JSM 610LA; JEOL Ltd, Tokyo, Japan).

\section{Sample preparation}

Three hundred samples of N1 acrylic resin (Artigos Odontológicos Clássico, São Paulo, Brazil) were manufactured. Of these 300 samples, 100 were used for the color stability and microhardness tests (each test was performed on the opposite side of the same sample) and 200 were used for the flexural strength tests (100 samples each for the tests before and after accelerated aging). Samples were divided into ten groups ( $\mathrm{n}=10)$, according to the NP type and concentration that was combined with the N1 acrylic resin, ie, without NPs (control group) and $1 \%, 2 \%$, or $2.5 \% \mathrm{ZnO}, \mathrm{TiO}_{2}$, or $\mathrm{BaSO}_{4}$ (for nine NP groups). ${ }^{22}$

Samples in the color and microhardness tests were fabricated by a metallic matrix from silicone rubber disks (Zetalabor $^{\circledR}$, Zhermack International, Rovigo, Italy) $3.0 \mathrm{~cm}$ in diameter and $0.3 \mathrm{~cm}$ in thickness. ${ }^{24,25}$ To create the molds, the disks were embedded into two-part flasks (Classico Dental Products, São Paulo, Brazil) with type IV dental stone (Durone, Dentsply, Petrópolis, Rio de Janeiro, Brazil). The flasks were maintained in a hydraulic press (Midas Dental Products Ltd, Sao Paulo, Brazil) for 2 minutes. After crystallization of the dental stone, the flasks were opened and the silicone disks removed.

Samples for the flexural strength test were fabricated from bars of colorless self-cured acrylic resin (Artigos Odontológicos Clássico) that were produced by a metal pattern. The bars were finished with metal abrasives of different grits (320, 600, 800, and 1,200; Buehler, Lake Bluff, IL, USA) in an automatic polisher (Ecomet 250 Pro/Automet 250, Buehler). Each final bar had a uniform texture and surface, with final dimensions of $64 \times 10 \times 3.3 \times 9 \mathrm{~mm} .^{7,26}$ The bars were placed in microwave flasks. Type IV stone plaster and extra-hard laboratory silicone were used to facilitate sample deflasking. After plaster crystallization in the final inclusion, the flasks were opened, the bars were removed, and molds obtained.

The N1 acrylic resin was proportioned and manipulated according to the manufacturer's instructions. Briefly, OndaCryl polymer was used in an ideal volume ratio of three parts powder to one part liquid ( $21 \mathrm{mg}$ to $7 \mathrm{~mL}$ ). The mixture was mixed with a spatula for a few seconds in a glass pot, and the pot was closed. After the plastic phase was reached, resin was inserted into the molds in a microwave flask. NPs were incorporated at the moment of resin manipulation. The resin and NPs were weighed on a digital precision scale (BEL Equipamentos Analítico, São Paulo, Brazil), with NPs equivalent to $1 \%, 2 \%$, or $2.5 \%$ of the acrylic resin weight. NPs at the three concentrations were hand-mixed with the acrylic resin powder, using a metal spatula in a glass pot. 
A counter-flask was positioned and raised in a hydraulic bench press (Midas Dental Products Ltd) with a weight of $1.250 \mathrm{kgf}$. The counter-flask was maintained in place for 2 minutes. Bench polymerization was performed for 30 minutes. The resins were polymerized in a microwave oven (model BM535BBHNA, Maxi, Brastemp, São Paulo, Brazil), with the following technical specifications: power of $1,300 \mathrm{~W}$, frequency of $60 \mathrm{~Hz}$, and current of $20 \mathrm{~A}$. The polymerization cycle was performed in a sequential treatment of 3 minutes at $30 \%, 4$ minutes at $0 \%$, and 3 minutes at $60 \%$ power, according to the manufacturer's instructions. After polymerization, the flasks were cooled naturally and opened. Samples were removed and finished with metallographic abrasives of $320,600,800$, and 1,200 grit, simulating the laboratory conditions for making ocular prostheses. The dimensions of each sample were measured by a precision digital caliper (Meba, Zagreb, Yugoslavia).

Samples were stored in distilled water at $37^{\circ} \mathrm{C}$ for 24 hours (Cienlab, Campinas, São Paulo, Brazil) for hydration and residual monomer release. Thereafter, the samples were subjected to color stability, microhardness, and flexural strength tests, with each test being performed before and after 1,008 hours of accelerated aging.

\section{Color stability test}

Samples were submitted to initial chromatic analysis by an ultraviolet-visible reflection spectrophotometer (model UV-2450, Shimadzu Corporation, Kyoto, Japan). Color alterations were calculated with the $\mathrm{L}^{*} \mathrm{a} * \mathrm{~b}$ * system established by the Commission Internationale de 1'Eclairage. ${ }^{27}$ This system allows the mean value of color variation $(\Delta \mathrm{E})$ between two readings to be calculated by the formula: $\Delta \mathrm{E}=\left[(\Delta \mathrm{L})^{2}+(\Delta \mathrm{a})^{2}+(\Delta \mathrm{b})^{2}\right]^{1 / 2}$.

\section{Microhardness test}

Knoop microhardness was determined according to American Society for Testing and Materials specification E384-1128 using a microhardener (HMV-2T; Shimadzu Corporation) with a $25 \mathrm{~g}$ load for 10 seconds. For each sample, five measurements were performed. Each sample was placed $500 \mu \mathrm{m}$ from any other sample and $500 \mu \mathrm{m}$ from the sample boards.

\section{Flexural strength test}

This test was performed using the rupture modulus with a constant velocity of $5 \mathrm{~mm} / \mathrm{min}$ until fracturing was detected. Samples were positioned in a universal testing machine (EMIC, São José dos Pinhais, São Paulo, Brazil) following the three-point technique, with a distance of $50 \mathrm{~mm}$ between the sample and sides of the machine. A weight of $100 \mathrm{~kg}$ was applied, and the maximum fracture resistance was recorded in $\mathrm{MPa}^{29}$

\section{Accelerated aging}

After initial tests, accelerated aging was carried out in an aging chamber (Equilam, Diadema, Brazil), according to American Society for Testing and Materials specification G53. ${ }^{30}$ Specimens were submitted to periods of alternating ultraviolet light and condensation of oxygen-saturated distilled water under conditions of heat and $100 \%$ humidity. Each aging cycle was performed over 12 hours. Specifically, the sample was irradiated with ultraviolet light for 8 hours at $60^{\circ} \mathrm{C} \pm 3^{\circ} \mathrm{C}$, and then condensation took place without light for 4 hours at $45^{\circ} \mathrm{C} \pm 3^{\circ} \mathrm{C}$. This process simulated the deterioration caused by rainwater, dew, and ultraviolet energy (UV-B) from direct and indirect sunlight. Samples were submitted to 1,008 hours of accelerated aging, and then new color, microhardness, and flexural strength tests were performed.

\section{Statistical analysis}

The effects of different types and concentrations of NPs on the acrylic resin properties were analyzed by nested analysis of variance. The concentration factor was nested in the NP factor because less than all concentration levels occur within each NP level. Significant differences were compared by Tukey's honestly significant difference test $(\alpha=0.05)$.

\section{Results and discussion}

The results indicated that the null hypothesis should be rejected. NPs directly influenced the acrylic resin properties, providing general higher color stability and microhardness values and lower flexural strength values, in comparison to the control group, after accelerated aging.

\section{Elemental component analysis of the resin}

Combined EDS-SEM analysis revealed that before NP incorporation, elements of the NPs were present in the composition of the acrylic resin polymer (Figures 1 and 2), although at extremely small amounts. Specifically, the EDS graphic (Figure 1) was predominated by peaks of carbon (70.37\%) and oxygen (28.65\%), which are present in polymethylmethacrylate molecules. Peaks of elements of the studied NPs represented $0.08 \% \mathrm{Ti}, 0.01 \% \mathrm{Ba}$, and insignificant $\mathrm{Zn}$. The minute amounts of these NPs in the acrylic resin justified the testing of higher concentrations of these NPs 


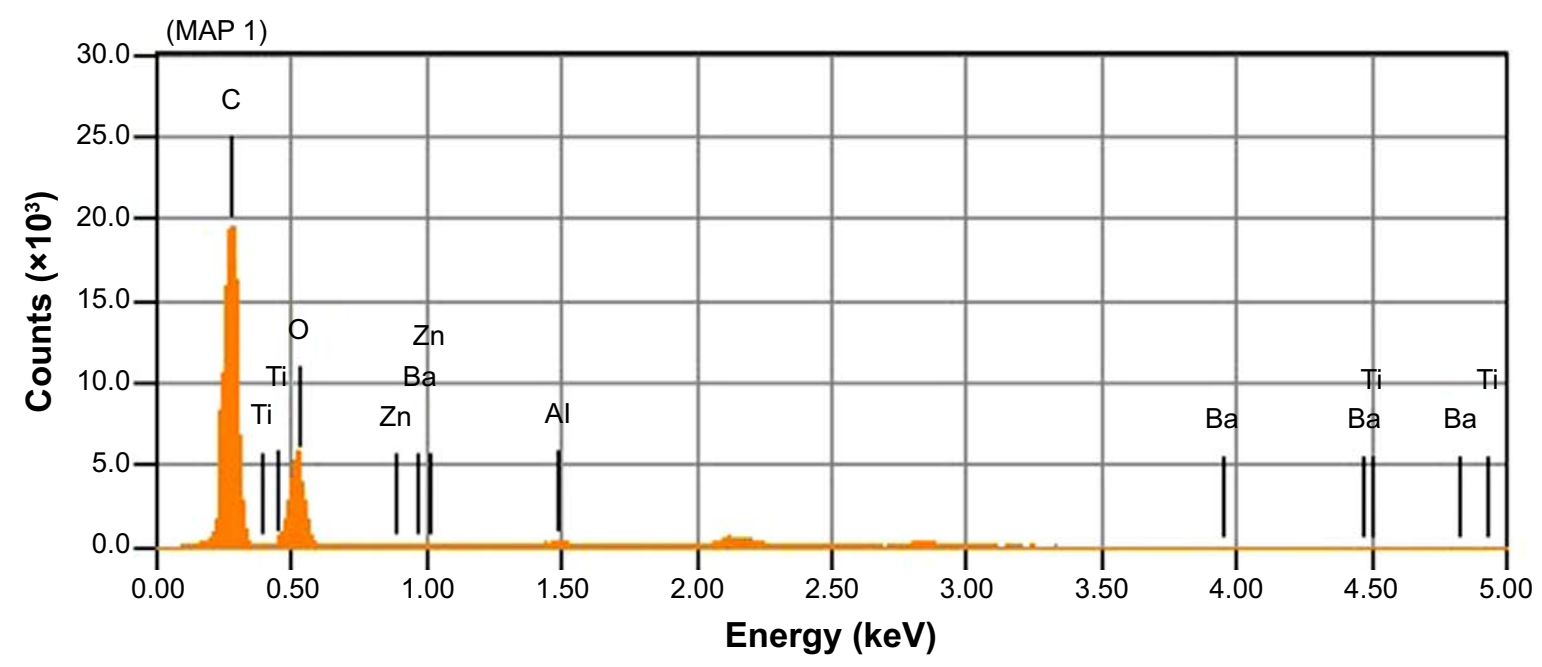

Figure I Energy dispersive spectroscopy analysis of acrylic resin polymer.

(1\%-2.5\%). The studied NP concentrations are consistent with those in other studies in the literature, especially Han et al who evaluated the effects of $0.5 \%-3 \%$ nano-oxides on the properties of a commercially available pigmented maxillofacial silicone elastomer. ${ }^{22}$

\section{Color stability}

There were statistically significant differences in color stability for the factors of NP and concentration, with concentration nested in NP (Table 1). All samples showed considerable color changes $(\Delta \mathrm{E}>0$, Table 2$)$. The control and $\mathrm{BaSO}_{4}$ groups presented significantly higher values of color change compared with the other groups (Table 2).

Most polymers possess functional groups in their molecular chains, which are able to absorb ultraviolet light. When a polymeric molecule absorbs ultraviolet light, excessive energy leads to an unstable structural state. The excited molecule tends to disperse the excess energy, re-establishing

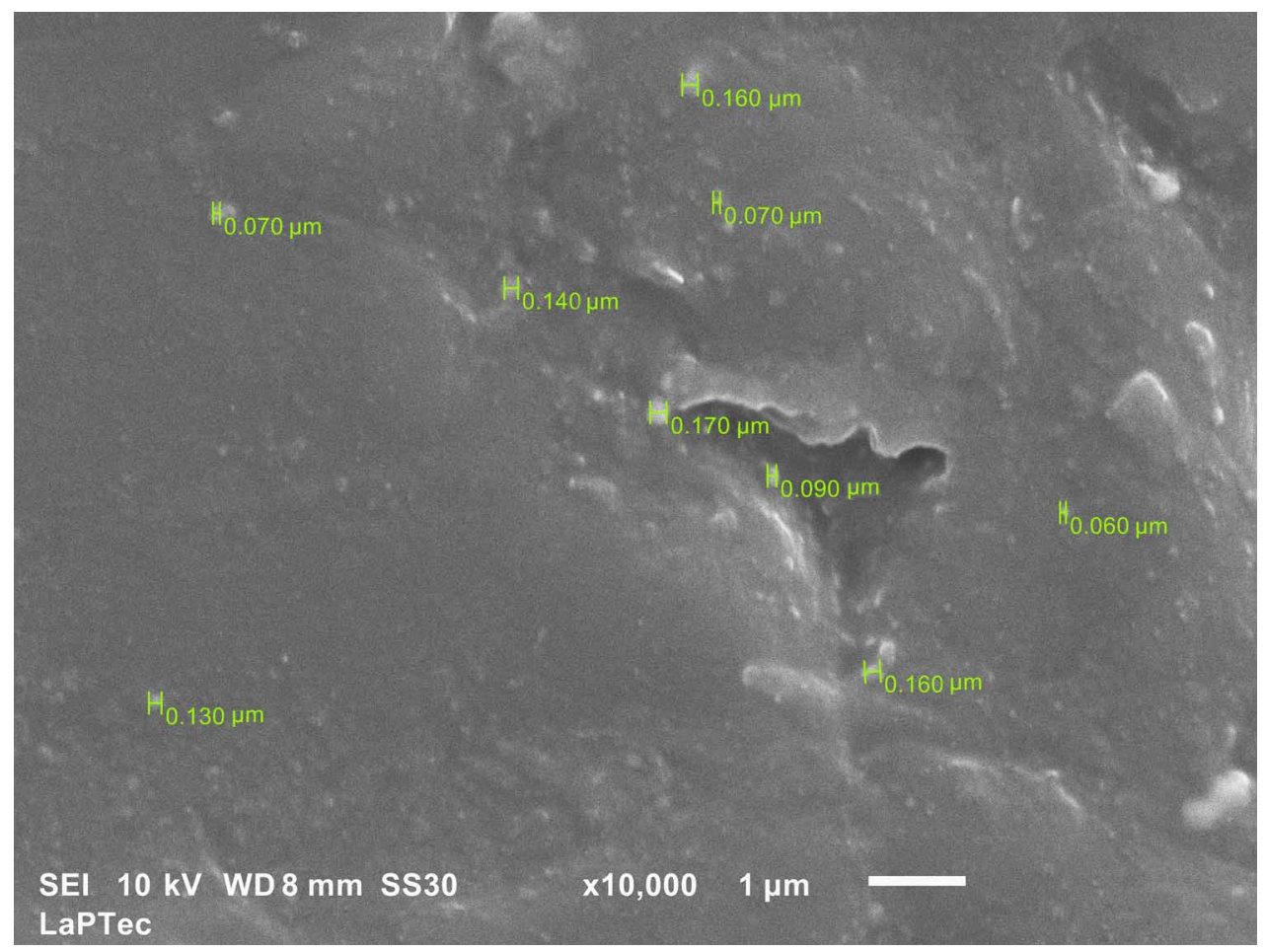

Figure 2 Scanning electron microscopy image of acrylic resin polymer.

Note: Green highlights correspond to nanoparticles and their measurements.

Abbreviations: SEI, secondary electron imaging; WD, working distance; SS, spot size. 
Table I Two-way nested analysis of variance for change in color $(\Delta \mathrm{E})$

\begin{tabular}{lllllll}
\hline Variation factor & df & SS sequential & SS adjusted & MS adjusted & $\boldsymbol{F}$ & P-value \\
\hline Nanoparticle & 3 & 405.4 & 405.4 & 135.1 & 330.7 & $<0.00 I^{*}$ \\
Concentration (nanoparticle) & 6 & 133.3 & 133.3 & 22.2 & 54.4 & $<0.00 I^{*}$ \\
Error & 90 & 36.8 & 36.8 & 0.4 & & \\
Total & 99 & 575.4 & & &
\end{tabular}

Note: $* p<0.05$ denotes statistically significant difference.

Abbreviations: $d f$, degrees of freedom; SS, sum of squares; MS, mean of squares.

a stable structure. This dispersion event leads to rupture and photochemical degradation of the molecule, which contributes to material degradation, color or brightness changes, loss of opacity, cracks, and increased stiffness. ${ }^{31-33}$ Extrinsic factors (eg, absorption or adsorption of external substances) $)^{32,34}$ and intrinsic factors (eg, matrix alterations, which are very common with aging $)^{35}$ may also have contributed to the observed color changes. ${ }^{36,37}$

In general, the samples incorporating NPs showed significantly greater color stability compared with the control group (Table 2). This finding is consistent with the results of other studies, ${ }^{10,11,38-40}$ which showed that addition of $\mathrm{ZnO}, \mathrm{TiO}_{2}$, or $\mathrm{BaSO}_{4}$ to polymeric materials can increase the longevity of maxillofacial prostheses by promoting maintenance of color. $^{10,12,38-40}$

NPs are widely used, especially in sunscreen lotions, as inorganic absorbers of ultraviolet light. . $2,38,41,42$ Inorganic NPs differ from some organic ultraviolet absorbers, in that they do not migrate in the polymeric matrix. Moreover, their photostability and thermal stability are not problematic, even over decades..$^{42}$ NPs are smaller than the ultraviolet electromagnetic wave; thus, when ultraviolet light acts on NPs, part of the wave is dissipated while the rest is simultaneously absorbed. On the basis of these physical principles, protection may result from the absorption and dissipation of ultraviolet light by NPs, which act as a physical barrier by reflecting the light that reaches the prosthesis ${ }^{22}$ and preventing discoloration. ${ }^{40,41,43}$

Different types and proportions of NPs were used in this study, with different levels of color stability, not all of which protected against color degradation of the resin (Table 2). These differences may be due to variations in the amount of organic impurities mixed with NPs after different handling processes by the manufacturers. Additionally, different NPs may interact differently with various polymer types. ${ }^{10,39}$ As the NP concentration increased, the $\mathrm{ZnO}$ and $\mathrm{TiO}_{2}$ groups showed significant reductions in the color change values. Among the NP groups, the $\mathrm{TiO}_{2}$ groups, especially the group with the $2.5 \%$ concentration, exhibited the least degree of color change (Table 2). Similarly, Han et $\mathrm{al}^{22}$ found that $2.5 \%$
$\mathrm{TiO}_{2}$ showed the best color stability results in their evaluation of nano-oxides incorporated into a facial silicone. Various studies have shown that $\mathrm{TiO}_{2}$ exhibits the best color protection results among studied NPs. ${ }^{10,12,40}$

As a NP decreases in size, it offers increasing protection against ultraviolet light. ${ }^{22,44,45}$ Thus, we believe that particles of $\mathrm{TiO}_{2}$ are smaller than those of $\mathrm{ZnO}$ or $\mathrm{BaSO}_{4}$, and that $\mathrm{TiO}_{2}$ particles strongly link with acrylic resin particles to prevent resin degradation. In addition to NP size, the enhanced properties that arise from adding NPs to a polymer matrix may be attributed to the higher surface energy and chemical reactivity of the particles, which allow them to interact with the polymer matrix and form a three-dimensional network within the silicone polyethylene backbone. ${ }^{46}$

According to the National Bureau of Standards, a color change is considered to be very low when $\Delta \mathrm{E}$ is less than 1 , clinically acceptable when $\Delta \mathrm{E}$ is between 1 and 3 , and clinically noticeable when $\Delta \mathrm{E}$ exceeds $3 .^{39}$ In this study, the lowest mean color change value was 6.89 , indicating that all of the evaluated groups had inappropriate degrees of color change.

\section{Microhardness}

Significant differences in microhardness were observed for all analyzed factors and interactions (Table 3). In general, the

Table 2 Average values of color change $(\Delta \mathrm{E})$

\begin{tabular}{lll}
\hline Concentration & Nanoparticle & Color change $(\Delta \mathrm{E})$ \\
\hline Not added & Control & $13.74(0.55) \mathrm{A}$ \\
$1 \%$ & $\mathrm{ZnO}$ & $12.66(0.45) \mathrm{B}$ \\
& $\mathrm{TiO}_{2}$ & $10.22(0.58) \mathrm{C}$ \\
& $\mathrm{BaSO}_{4}$ & $12.52(0.45) \mathrm{B}$ \\
$2 \%$ & $\mathrm{ZnO}$ & $10.10(0.92) \mathrm{C}$ \\
& $\mathrm{TiO}_{2}$ & $8.78(0.61) \mathrm{D}$ \\
& $\mathrm{BaSO}_{4}$ & $13.38(0.56) \mathrm{AB}$ \\
$2.5 \%$ & $\mathrm{ZnO}^{2}$ & $9.14(1.07) \mathrm{D}$ \\
& $\mathrm{TiO}_{2}$ & $6.89(0.38) \mathrm{E}$ \\
& $\mathrm{BaSO}_{4}$ & $14.02(0.47) \mathrm{A}$ \\
\hline
\end{tabular}

Notes: Data are shown as the mean (standard deviation). Different uppercase letters indicate statistically significant differences between the groups, by Tukey's test $(P<0.05)$. 
Table 3 Three-way nested analysis of variance for microhardness (Knoop)

\begin{tabular}{|c|c|c|c|c|c|c|}
\hline Variation factor & $d f$ & SS sequential & SS adjusted & MS adjusted & $\boldsymbol{F}$ & P-value \\
\hline Period & I & 13.2 & 6.7 & 6.7 & 36.6 & $<0.00 I^{*}$ \\
\hline Nanoparticle & 3 & 45.2 & 45.2 & 15.1 & 82.5 & $<0.00 I^{*}$ \\
\hline Period $\times$ nanoparticle & 3 & 37.9 & 38.0 & 12.6 & 69.3 & $<0.00 I^{*}$ \\
\hline Concentration (nanoparticle) & 6 & 16.8 & 16.8 & 2.8 & 15.4 & $<0.00 I^{*}$ \\
\hline Period $\times$ concentration (nanoparticle) & 6 & 7.2 & 7.1 & 1.2 & 6.5 & $<0.00 I^{*}$ \\
\hline Error & 180 & 32.8 & 32.8 & 0.2 & & \\
\hline Total & 199 & 153.0 & & & & \\
\hline
\end{tabular}

Note: $* P<0.05$ denotes a statistically significant difference.

Abbreviations: $d f$, degrees of freedom; SS, sum of squares; MS, mean of squares.

microhardness values increased with aging, except for the control and $\mathrm{ZnO}$ groups (Table 4). The increased microhardness after accelerated aging was probably a result of the complete resin polymerization that occurred when the samples were subjected to different types of energy (eg, high temperature and water condensation inside the aging chamber). ${ }^{47,48}$ After aging, the $1 \%$ and $2 \% \mathrm{TiO}_{2}$ groups exhibited significantly higher microhardness values compared with the other NP groups (Table 4). Similar to the color change results, this result can be explained by the presumably smaller size of $\mathrm{TiO}_{2}$ compared with $\mathrm{ZnO}$ and $\mathrm{BaSO}_{4}$, which would promote tight linking to the resin particles and prevent their degradation. ${ }^{22,44,45}$

Specification 12 of the American Dental Association states that the surface microhardness of denture base acrylic resin must be at least 15 Knoop. ${ }^{24,49}$ As ocular prostheses are subjected to fewer impacts of lower intensity compared with denture bases, the microhardness values found in this study can be considered satisfactory and clinically acceptable.

\section{Flexural strength}

Statistically significant differences in flexural strength were observed in the interaction between the period and NP factors

Table 4 Average values for microhardness (Knoop)

\begin{tabular}{llll}
\hline \multirow{2}{*}{ Concentration Nanoparticle } & \multicolumn{2}{l}{ Period } \\
\cline { 3 - 4 } & & Initial & After aging \\
\hline Not added & Control & $20.16(0.35) \mathrm{ABa}$ & $20.04(0.25) \mathrm{Ca}$ \\
$1 \%$ & $\mathrm{ZnO}$ & $20.12(0.33) \mathrm{ABa}$ & $19.57(0.57) \mathrm{CDa}$ \\
& $\mathrm{TiO}_{2}$ & $20.16(0.44) \mathrm{ABa}$ & $20.93(0.40) \mathrm{Bb}$ \\
& $\mathrm{BaSO}_{4}$ & $19.26(0.31) \mathrm{Ba}$ & $19.95(0.23) \mathrm{Ca}$ \\
& $\mathrm{ZnO}^{2}$ & $19.64(0.29) \mathrm{ABCa}$ & $19.11(0.78) \mathrm{Da}$ \\
& $\mathrm{TiO}_{2}$ & $20.31(0.29) \mathrm{Aa}$ & $21.76(0.34) \mathrm{Ab}$ \\
& $\mathrm{BaSO}_{4}$ & $19.57(0.32) \mathrm{Ba}$ & $20.81(0.81) \mathrm{Bb}$ \\
$2.5 \%$ & $\mathrm{ZnO}$ & $19.50(0.49) \mathrm{Ba}$ & $18.59(0.28) \mathrm{Db}$ \\
& $\mathrm{TiO}_{2}$ & $19.88(0.34) \mathrm{ABCa}$ & $20.84(0.40) \mathrm{Bb}$ \\
& $\mathrm{BaSO}_{4}$ & $19.22(0.36) \mathrm{BCa}$ & $21.36(0.38) \mathrm{ABb}$ \\
\hline
\end{tabular}

Notes: Data are shown as the mean (standard deviation). Different uppercase letters indicate statistically significant differences between the groups, while different lowercase letters indicate statistically significant differences between the periods, by Tukey's test $(P<0.05)$.
(Table 5). Before aging, the NP groups at all concentrations showed significantly lower flexural strength values compared with the control group (Table 6). Most likely, the incorporation of NPs in the resin matrix hindered cross-linking of the polymer chains and had a degrading effect. ${ }^{33}$ Furthermore, more so than any other property examined in this study, flexural strength is directly influenced by NP type. ${ }^{50}$ Other possible reasons for the decreased flexural strength with incorporation of NPs include the increased porosity with NP addition and agglomerations around the incorporated NPs, which favors fracture. ${ }^{51}$

There was a significant difference in flexural strength between the periods before and after aging for the control and $\mathrm{TiO}_{2}$ groups. Addition of $\mathrm{TiO}_{2}$ resulted in lower flexural strength values after aging, most likely due to the nature of this NP (Table 6). Despite the very small size of $\mathrm{TiO}_{2}$ NPs, they are difficult to disperse in organic solvents and tend to agglomerate easily. ${ }^{50}$ The agglomerations can reach micrometer scales that are detrimental to flexural strength, because large porous areas may appear around them, increasing the likelihood of fracture. ${ }^{52}$

The increased risk of fracture is one reason why using a higher NP concentration was not feasible in the current study. Although NPs can reinforce the polymer matrix, the filler content must be maintained at an appropriate level because of the higher surface energy and chemical reactivity of the NPs. ${ }^{46}$ If not appropriately maintained, the NPs may agglomerate. When the acrylic resin is under external forces, the agglomerated particles act as stress-concentrating centers in the resin matrix, thereby decreasing its mechanical strength. ${ }^{17}$

Han et al observed that nano-oxide particles incorporated in silicone elastomer at a concentration of $2.0 \%$ maintained their original size and improved the mechanical properties of silicone. However, when the concentration was increased to $3.0 \%$, the SEM images demonstrated agglomeration of all the nano-oxides. Nevertheless, incorporation of nano-oxides improved a wide range of mechanical properties when the NP 
Table 5 Three-way nested analysis of variance for flexural strength ( $\mathrm{MPa}$ )

\begin{tabular}{lllllll}
\hline Variation factor & $\mathbf{d f}$ & SS sequential & SS adjusted & MS adjusted & $\boldsymbol{F}$ & $\boldsymbol{P}$-value \\
\hline Period & $\mathrm{I}$ & $13,014.3$ & $15,065.5$ & $15,065.5$ & 96.9 & $<0.001 *$ \\
Nanoparticle & 3 & $3,329.7$ & $3,329.7$ & $1,109.9$ & 7.1 & $<0.001 *$ \\
Period $\times$ nanoparticle & 3 & $8,141.4$ & $8,141.4$ & $2,713.8$ & 17.5 & $<0.001 *$ \\
Concentration (nanoparticle) & 6 & 503.5 & 503.5 & 83.9 & 0.5 & 0.78 \\
Period $\times$ concentration (nanoparticle) & 6 & $1,052.8$ & $1,052.8$ & 175.5 & 1.1 \\
Error & 180 & $27,999.4$ & $27,999.4$ & 155.6 & \\
Total & 199 & $54,041.1$ & & & \\
\hline
\end{tabular}

Note: $* P<0.05$ denotes a statistically significant difference.

Abbreviations: $d f$, degrees of freedom; SS, sum of squares; MS, mean of squares.

concentration ranged between $2.0 \%$ and $2.5 \%$ by weight. ${ }^{17}$ Overall, our findings and the observations from previous studies suggest that these NPs require some surface modification to reduce agglomeration and improve their dispersion in resin matrix. ${ }^{50}$

We also believe that the increased microhardness due to incorporation of NPs may have reduced the flexural strength. As the microhardness increases, a material becomes more friable, and therefore more susceptible to fracture. According to International Organization for Standardization 1567, the flexural strength of microwave-polymerized acrylic resin should be at least $65 \mathrm{MPa} .{ }^{53}$ Although the flexural strength values decreased with addition of NPs, in this study, all of the values for flexural strength were satisfactory and clinically acceptable.

\section{Summary}

The samples were subjected to 1,008 hours of accelerated aging, equivalent to one year of clinical use. ${ }^{16,54}$ Ultraviolet light, humidity, and heat caused polymer degradation by altering the color stability, microhardness, and flexural strength of N1 acrylic resin. Accelerated aging may have caused degradation of the organic resin matrix, involving hydrolysis and decomposition of the polymeric chain. ${ }^{32,40,55}$ The importance of maintaining and improving the properties of acrylic resin for ocular prosthesis use are well known. NPs are increasingly being used to improve the performance of

Table 6 Average values of flexural strength (MPa) for nanoparticle type and period, independent of concentration

\begin{tabular}{lll}
\hline Nanoparticle type & \multicolumn{2}{l}{ Period } \\
\cline { 2 - 3 } & Before aging & After aging \\
\hline Control & $112.23(9.04) \mathrm{Aa}$ & $76.45(17.1 \mathrm{I}) \mathrm{ABb}$ \\
$\mathrm{ZnO}$ & $84.85(15.34) \mathrm{Ca}$ & $80.65(12.31) \mathrm{Aa}$ \\
$\mathrm{TiO}_{2}$ & $97.08(13.35) \mathrm{Ba}$ & $66.91(11.21) \mathrm{Bb}$ \\
$\mathrm{BaSO}_{4}$ & $83.31(10.62) \mathrm{Ca}$ & $75.82(9.96) \mathrm{Aba}$ \\
\hline
\end{tabular}

Notes: Data are shown as the mean (standard deviation). Different uppercase letters indicate statistically significant differences between the groups, while different lowercase letters indicate statistically significant differences between the periods, by Tukey's test $(P<0.05)$. polymeric materials. Therefore, more studies are required to elucidate the effects of NPs, and the mechanisms underlying these effects, on the physical and mechanical properties of prosthesis materials.

\section{Conclusion}

Considering the limitations of an in vitro study, it can be concluded that:

- Accelerated aging, through ultraviolet light, humidity, and heat, was a causative factor of polymer degradation, altering the properties of $\mathrm{N} 1$ acrylic resin

- Incorporation of NPs, especially $2.5 \% \mathrm{TiO}_{2}$, helped in maintaining color stability and microhardness after aging

- Flexural strength was relatively impaired by addition of NPs, although the results were within the clinically acceptable standard.

\section{Acknowledgment}

This work was supported by the São Paulo Research Foundation (Process 2012/02907-0).

\section{Disclosure}

The authors report no conflicts of interest in this work.

\section{References}

1. Moreno A, Goiato MC, dos Santos DM, Haddad MF, Pesqueira AA, Bannwart LC. Effect of different disinfectants on the microhardness and roughness of acrylic resins for ocular prosthesis. Gerodontology. 2013;30(1):32-39.

2. Markt JC, Lemon JC. Extraoral maxillofacial prosthetic rehabilitation at the M. D. Anderson Cancer Center: a survey of patient attitudes and opinions. J Prosthet Dent. 2001;85(6):608-613.

3. Trawnik WR. Care of the ocular prosthesis. Adv Ophthalmic Plast Reconstr Surg. 1990;8:146-148.

4. Goiato MC, Nicolau EI, Mazaro JV, et al. Mobility, aesthetic, implants, and satisfaction of the ocular prostheses wearers. J Craniofac Surg. 2010;21(1):160-164.

5. Goiato MC, dos Santos DM, Haddad MF, Pesqueira AA, de Carvalho Dekon SF, Zavanelli AC. Most frequent tumors in maxillofacial area rehabilitated through surgical reconstruction and prostheses. J Craniofac Surg. 2010;21(2):396-399. 
6. Fernandes AU, Goiato MC, dos Santos DM. Effect of weathering and thickness on the superficial microhardness of acrylic resin and ocular button. Cont Lens Anterior Eye. 2009;32(6):283-287.

7. Fernandes AU, Portugal A, Veloso LR, Goiato MC, Santos DM. Assessment of the flexural strength of two heat-curing acrylic resins for artificial eyes. Braz Oral Res. 2009;23(3):263-267.

8. Fernandes AU, Goiato MC, Dos Santos DM. Effect of weathering and thickness on roughness of acrylic resin and ocular button. Cont Lens Anterior Eye. 2010;33(3):124-127.

9. Goiato MC, dos Santos DM, Gennari-Filho H, Zavanelli AC, Dekon SF, Mancuso DN. Influence of investment, disinfection, and storage on the microhardness of ocular resins. J Prosthodont. 2009;18(1):32-35.

10. Kiat-amnuay S, Beerbower M, Powers JM, Paravina RD. Influence of pigments and opacifiers on color stability of silicone maxillofacial elastomer. J Dent. 2009;37(Suppl 1):e45-e50.

11. dos Santos DM, Goiato MC, Moreno A, Pesqueira AA, Haddad MF. Influence of pigments and opacifiers on color stability of an artificially aged facial silicone. J Prosthodont. 2011;20(3):205-208.

12. Kiat-Amnuay S, Mekayarajjananonth T, Powers JM, Chambers MS, Lemon JC. Interactions of pigments and opacifiers on color stability of MDX4-4210/type A maxillofacial elastomers subjected to artificial aging. J Prosthet Dent. 2006;95(3):249-257.

13. Beasley DG, Meyer TA. Characterization of the UVA protection provided by avobenzone, zinc oxide, and titanium dioxide in broad-spectrum sunscreen products. Am J Clin Dermatol. 2010;11(6):413-421.

14. Newman MD, Stotland M, Ellis JI. The safety of nanosized particles in titanium dioxide- and zinc oxide-based sunscreens. $\mathrm{J} \mathrm{Am} \mathrm{Acad}$ Dermatol. 2009;61(4):685-692.

15. Goiato MC, Haddad MF, Sinhoreti MA, dos Santos DM, Pesqueira AA, Moreno A. Influence of opacifiers on dimensional stability and detail reproduction of maxillofacial silicone elastomer. Biomed Eng Online. 2010;9:85

16. Goiato MC, Haddad MF, Santos DM, Pesqueira AA, Moreno A. Hardness evaluation of prosthetic silicones containing opacifiers following chemical disinfection and accelerated aging. Braz Oral Res. 2010;24(3):303-308.

17. Han Y, Kiat-Amnuay S, Powers JM, Zhao Y. Effect of nano-oxide concentration on the mechanical properties of a maxillofacial silicone elastomer. J Prosthet Dent. 2008;100(6):465-473.

18. Khan AA, Alam MM. Synthesis, characterization and analytical applications of a new and novel 'organic-inorganic' composite material as a cation exchanger and $\mathrm{Cd}(\mathrm{II})$ ion-selective membrane electrode: polyaniline Sn(IV) tungstoarsenate. React Funct Polym. 2003;55(3):277-290.

19. Hayashi S, Fujiki K, Tsubokawa N. Grafting of hyperbranched polymers onto ultrafine silica: postgraft polymerization of vinyl monomers initiated by pendant initiating groups of polymer chains grafted onto the surface. React Funct Polym. 2000;46(2):193-201.

20. Koziej D, Fischer F, Kranzlin N, Caseri WR, Niederberger M. Nonaqueous $\mathrm{TiO}_{2}$ nanoparticle synthesis: a versatile basis for the fabrication of self-supporting, transparent, and UV-absorbing composite films. ACS Appl Mater Interfaces. 2009;1(5):1097-1104.

21. Tang E, Cheng G, Pang X, Ma X, Xing F. Synthesis of nano-ZnO/ poly(methyl methacrylate) composite microsphere through emulsion polymerization and its UV-shielding property. Colloid Polym Sci. 2006;284(4):422-428.

22. Han Y, Zhao Y, Xie C, Powers JM, Kiat-Amnuay S. Color stability of pigmented maxillofacial silicone elastomer: effects of nano-oxides as opacifiers. J Dent. 2010;38 Suppl 2:e100-e105.

23. Liu G, Li Y-F, Yan F-Y, Zhao Z-X, Zhou L-C, Xue Q-J. Effect of nanoscale $\mathrm{SiO}_{2}$ and $\mathrm{TiO}_{2}$ as the fillers on the mechanical properties and aging behavior of linear low-density polyethylene/low-density polyethylene blends. Journal of Polymers and the Environment. 2005;13(4):339-348.

24. Goiato MC, Dos Santos DM, Baptista GT, Moreno A, Andreotti AM, Dekon SF. Effect of thermal cycling and disinfection on microhardness of acrylic resin denture base. J Med Eng Technol. 2013;37(3): 203-207.
25. Goiato MC, Dos Santos DM, Baptista GT, et al. Effect of thermal cycling and disinfection on colour stability of denture base acrylic resin. Gerodontology. 2013;30(4):276-282.

26. Goiato MC, dos Santos DM, Moreno A, Iyda MG, Rezende MC, Haddad MF. Effect of disinfection and storage on the flexural strength of ocular prosthetic acrylic resins. Gerodontology. 2012;29(2):e838-e844.

27. Commission Internationale de l'Eclairage. Colorimetry. 2004. Available from: https://law.resource.org/pub/us/cfr/ibr/003/cie.15.2004.pdf. Accessed September 20, 2014.

28. American Society for Testing Materials International. Standard Test Method for Knoop and Vickers Hardness of Materials. 2012. Available from: http://www.astm.org/Standards/B277.htm. Accessed September 20, 2014.

29. Archadian N, Kawano F, Ohguri T, Ichikawa T, Matsumoto N. Flexural strength of rebased denture polymers. J Oral Rehabil. 2000;27(8):690-696.

30. ASTM International. ASTM G154-12a. Standard practice for operating fluorescent ultraviolet (UV) lamp apparatus for exposure of nonmetallic materials. West Conshohocken, PA: American Society for Testing and Materials International; 2000. Available from: http://www.astm. org/Standards/G154.htm. Accessed November 19, 2014.

31. Goiato MC, Santos DM, Souza JF, Moreno A, Pesqueira AA. Chromatic stability of acrylic resins of artificial eyes submitted to accelerated aging and polishing. J Appl Oral Sci. 2010;18(6):641-645.

32. dos Santos DM, Goiato MC, Sinhoreti MA, Fernandes AU, Ribeiro Pdo P, Dekon SF. Color stability of polymers for facial prosthesis. J Craniofac Surg. 2010;21(1):54-58.

33. Anusavice KJ. Phillips' Science Of Dental Materials. 11th ed. Philadelphia, PA, USA: Saunders; 2003.

34. Abu-Bakr N, Han L, Okamoto A, Iwaku M. Color stability of compomer after immersion in various media. $J$ Esthet Dent. 2000;12(5): 258-263.

35. Iazzetti G, Burgess JO, Gardiner D, Ripps A. Color stability of fluoride-containing restorative materials. Oper Dent. 2000;25(6): 520-525.

36. Joiner A. Tooth colour: a review of the literature. J Dent. 2004; 32(Suppl 1):3-12.

37. Villalta P, Lu H, Okte Z, Garcia-Godoy F, Powers JM. Effects of staining and bleaching on color change of dental composite resins. J Prosthet Dent. 2006;95(2):137-142.

38. Filie Haddad M, Coelho Goiato M, Micheline Dos Santos D, Moreno A, Filipe D'almeida N, Alves Pesqueira A. Color stability of maxillofacial silicone with nanoparticle pigment and opacifier submitted to disinfection and artificial aging. J Biomed Opt. 2011;16(9): 095004.

39. Kiat-Amnuay S, Lemon JC, Powers JM. Effect of opacifiers on color stability of pigmented maxillofacial silicone A-2186 subjected to artificial aging. J Prosthodont. 2002;11(2):109-116.

40. Goiato MC, Haddad MF, Pesqueira AA, Moreno A, Dos Santos DM, Bannwart LC. Effect of chemical disinfection and accelerated aging on color stability of maxillofacial silicone with opacifiers. J Prosthodont. 2011;20(7):566-569.

41. Pinnell SR, Fairhurst D, Gillies R, Mitchnick MA, Kollias N. Microfine zinc oxide is a superior sunscreen ingredient to microfine titanium dioxide. Dermatol Surg. 2000;26(4):309-314.

42. Tran NH, Scarbecz M, Gary JJ. In vitro evaluation of color change in maxillofacial elastomer through the use of an ultraviolet light absorber and a hindered amine light stabilizer. J Prosthet Dent. 2004;91(5):483-490.

43. Gasparro FP, Mitchnick M, Nash JF. A review of sunscreen safety and efficacy. Photochem Photobiol. 1998;68(3):243-256.

44. Mancuso DN, Goiato MC, Santos DM. Color stability after accelerated aging of two silicones, pigmented or not, for use in facial prostheses. Braz Oral Res. 2009;23(2):144-148.

45. Goiato MC, Pesqueira AA, Santos DM, Dekon SF. Evaluation of hardness and surface roughness of two maxillofacial silicones following disinfection. Braz Oral Res. 2009;23(1):49-53. 
46. Watson S, Beydoun D, Scott J, Amal R. Preparation of nanosized crystalline $\mathrm{TiO}_{2}$ particles at low temperature for photocatalysis. J Nanopart Res. 2004;6(2):193-207.

47. Rattacaso RM, da Fonseca Roberti Garcia L, Aguilar FG, Consani S, de Carvalho Panzeri Pires-de-Souza F. Bleaching agent action on color stability, surface roughness and microhardness of composites submitted to accelerated artificial aging. Eur J Dent. 2011;5(2):143-149.

48. Goiato MC, Santos DM, Haddad MF, Pesqueira AA. Effect of accelerated aging on the microhardness and color stability of flexible resins for dentures. Braz Oral Res. 2010;24(1):114-119.

49. ANSI/ADA. Revised American National Standards/American Dental Association Specification n 12 for Denture Base Resins (R2007). New York, American National Standards Institute, 2002.

50. Xia Y, Zhang F, Xie H, Gu N. Nanoparticle-reinforced resin-based dental composites. J Dent. 2008;36(6):450-455.

51. Mansour MM, Wagner WC, Chu TM. Effect of mica reinforcement on the flexural strength and microhardness of polymethyl methacrylate denture resin. J Prosthodont. 2013;22(3):179-183.
52. Vallo CI. Flexural strength distribution of a PMMA-based bone cement. J Biomed Mater Res. 2002;63(2):226-236.

53. IOS. ISO 1567:199. Dentistry - Denture base polymers. Geneva: International Organization for Standardization; 1999. Available from: http://www.iso.org/iso/iso_catalogue/catalogue_ics/catalogue_detail_ ics.htm?csnumber $=20266$.

54. Mancuso DN, Goiato MC, Dekon SF, Gennari-Filho H. Visual evaluation of color stability after accelerated aging of pigmented and nonpigmented silicones to be used in facial prostheses. Indian J Dent Res. 2009;20(1):77-80.

55. Jin C, Nikawa H, Makihira S, Hamada T, Furukawa M, Murata H. Changes in surface roughness and colour stability of soft denture lining materials caused by denture cleansers. J Oral Rehabil. 2003;30(2):125-130.
International Journal of Nanomedicine

\section{Publish your work in this journal}

The International Journal of Nanomedicine is an international, peerreviewed journal focusing on the application of nanotechnology in diagnostics, therapeutics, and drug delivery systems throughout the biomedical field. This journal is indexed on PubMed Central, MedLine, CAS, SciSearch $®$, Current Contents ${ }^{\circledR} /$ Clinical Medicine,

\section{Dovepress}

Journal Citation Reports/Science Edition, EMBase, Scopus and the Elsevier Bibliographic databases. The manuscript management system is completely online and includes a very quick and fair peer-review system, which is all easy to use. Visit http://www.dovepress.com/ testimonials.php to read real quotes from published authors. 